\title{
Sources and sinks of acetone, methanol, and acetaldehyde in North Atlantic marine air
}

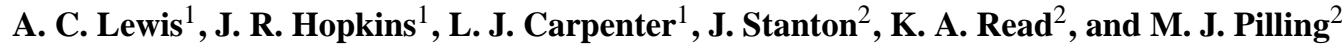 \\ ${ }^{1}$ Department of Chemistry, University of York, Heslington, York, YO10 5DD, UK \\ ${ }^{2}$ Department of Chemistry, University of Leeds, Leeds, LS2 9JT, UK
}

Received: 8 February 2005 - Published in Atmos. Chem. Phys. Discuss.: 9 March 2005

Revised: 13 June 2005 - Accepted: 28 June 2005 - Published: 1 August 2005

\begin{abstract}
Measurements of acetone, methanol, acetaldehyde and a range of non-methane hydrocarbons have been made in North Atlantic marine air at the Mace Head observatory. Under maritime conditions the combination of OVOCs (acetone, methanol and acetaldehyde) contributed up to $85 \%$ of the total mass of measured non methane organics in air and up to $80 \%$ of the $\mathrm{OH}$ radical organic sink, when compared with the sum of all other organic compounds including non-methane hydrocarbons, DMS and OH-reactive halocarbons (trichloromethane and tetrachloroethylene). The observations showed anomalies in the variance and abundance of acetaldehyde and acetone over that expected for species with a remote terrestrial emission source and $\mathrm{OH}$ controlled chemical lifetime. A detailed model incorporating an explicit chemical degradation mechanism indicated in situ formation during air mass transport was on timescales longer than the atmospheric lifetime of precursor hydrocarbons or primary emission. The period over which this process was significant was similar to that of airmass motion on intercontinental scales, and formation via this route may reproduce that of a widespread diffuse source. The model indicates that continued short chain OVOC formation occurs many days from the point of emission, via longer lived intermediates of oxidation such as organic peroxides and long chain alcohols.
\end{abstract}

\section{Introduction}

Oxygen containing organic species such as aldehydes, ketones and alcohols have been identified as exerting a substantial effect on atmospheric oxidative capacity and are widely distributed throughout the depth of the troposphere (Singh et al., 2001). Their almost ubiquitous presence in the atmosphere has led to a number of studies aiming to recre-

Correspondence to: J. R. Hopkins

(jh61@york.ac.uk) ate their behaviour using models, although discrepancies between some observed and calculated concentrations have led to the hypothesis that globally diffuse sources (such as sea-air exchange) may exist (Galbally and Kirstine, 2002 and Singh, 2003). Apportioning sources of oxygenated compounds is complicated since they may be released as primary emissions from anthropogenic sources (e.g. acetone from solvent usage, acetaldehyde from combustion, methanol from biofuel), biogenic sources (possibly all three species), but also as byproducts of atmospheric oxidation of hydrocarbon species. Their atmospheric lifetimes are relatively short $(24 \mathrm{~h}-12$ days), controlled by a combination of chemical, photolytic and physical removal processes and this has proved difficult to reconcile with their presence at both high altitudes and in remote locations. Many initial observations were made from aircraft, however datasets on longer time scales from ground observations are becoming available (Salisbury et al., 2003). There is still considerable uncertainty over sources and importantly whether the ocean plays a role in determining their abundance in maritime locations (Singh et al., 2001, 2003 and Williams et al., 2004).

The remote observatory at Mace Head $\left(53.3^{\circ} \mathrm{N}, 9.9^{\circ} \mathrm{W}\right)$, Ireland has been used on many occasions to study the longrange transport of atmospheric constituents of both natural and anthropogenic origin (Jennings et al., 1996; Lewis et al., 1997; Carslaw et al., 2000). In this study we have related abundance of acetone, methanol and acetaldehyde and a wide range of other organic species with airmass atmospheric trajectory over 5 days prior to arrival at Mace Head. We have paid particular attention to periods of "clean marine air" where airmasses have had no terrestrial input for many days. Observations under these conditions have been combined with physical parameters such as wind speed, time an airmass spent close to the sea surface, and the origin of the airmass. The variability of oxygenated compounds with respect to tracers of known anthropogenic (e.g. benzene, carbon monoxide (CO)), terrestrial biogenic (isoprene) and oceanic

(C) 2005 Author(s). This work is licensed under a Creative Commons License. 


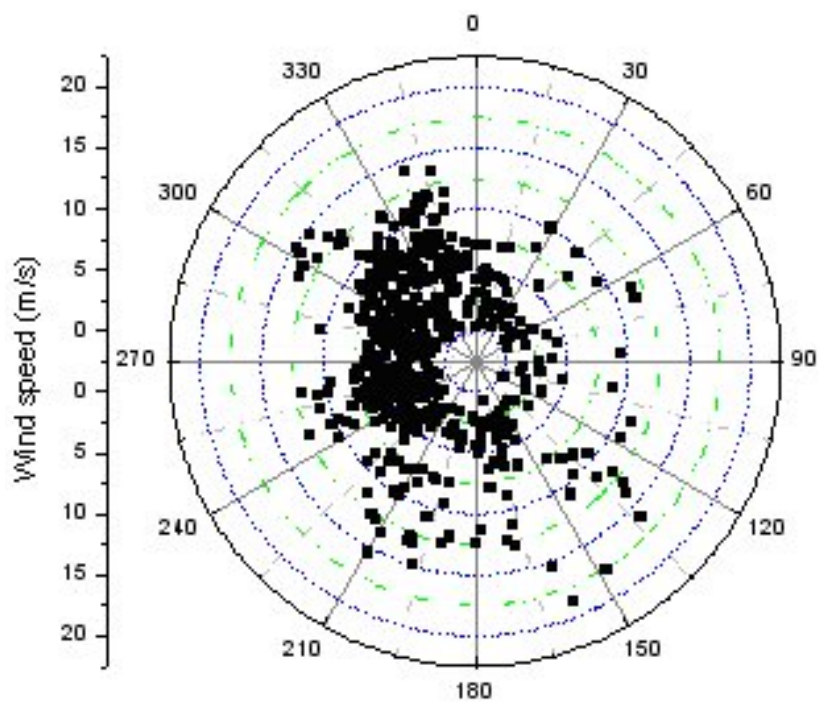

Fig. 1. Polar plot of local wind direction for organic observations during NAMBLEX 2002 experiment. Mace Head "clean" sector roughly $210^{\circ}$ to $330^{\circ}$ shows a significant number of samples allowing comprehensive study under these conditions

(di-methylsulphide (DMS), organohalogens, alkenes) origin has also been examined and some conclusions on possible sources for this location made.

\section{Methodology}

The measurements reported here were made over a 40-day period using a combination of gas chromatography (GC) techniques covering a wide variety of organic species, allowing a relatively complete characterisation of organic constituents in air of maritime origin. The measurements were made as part of the North Atlantic Marine Boundary Layer Experiment (NAMBLEX) at the Mace Head Observatory between July and September 2002 (Heard, 2005). $\mathrm{C}_{2}-\mathrm{C}_{7}$ hydrocarbons and small oxygenated molecules were determined using a dual channel Perkin Elmer GC-FID instrument coupled to a thermal desorption sampling system, see Hopkins et al. (2003) for full experimental detail. $\mathrm{C}_{3}+$ oxygenates were measured using an Agilent $6890 \mathrm{GC}$ with two independent columns connected via a valve modulator device (Hamilton and Lewis, 2003). Halocarbons (trichloromethane, tetrachloromethane and carbon tetrachloride) were measured using a Perkin Elmer GCquadrupole mass spectrometer operating in selected ion monitoring mode (Wevill and Carpenter, 2004). All samples were collected at shoreline from a height of $25 \mathrm{~m}$ through a low residence time (approximately $10 \mathrm{~s}$ ) 3/4 inch internal diameter teflon manifold. Other members of the NAMBLEX group, although not reported explicitly in this paper made an extensive suite of measurements on other inorganic gases and aerosols some of which have been used to provide alternative confirmations of air mass origin and characteristics. Back trajectory calculations have been made by the British Atmospheric Data Centre based on ECMWF reanalysis of satellite wind field data.

Atmospheric production of methanol, acetone and acetaldehyde was investigated using a zero dimensional box model which incorporated mechanisms taken from the MCM v3 (Saunders et al., 2003). The aim of the study was to identify the key precursor species for these lightweight OVOCs and investigate the timescales of their formation, however, no attempt was made to recreate any of the concentrations observed at the Mace Head site. The model was initialised with background organic and inorganic content representative of fresh emissions leaving a continental landmass (with the exception that OVOC concentrations were initially set to zero) and left to evolve over a ten day period. Dilution was not considered in the model and hence are only an upper limit of concentration within the airmass.

\section{Results}

\subsection{Classification of Air masses}

Although not always a good proxy for airmass origin, local wind direction gives a reasonable indication of frequency of cleaner westerly to more polluted easterly events. The polar plot of Fig. 1 highlights the significant number of samples from oceanic origins. Classification of air masses can be based on a range of gas phase and aerosol measurements. One such classification uses observations of $\mathrm{OH}$ and benzene and toluene, in conjunction with kinetic data to estimate the approximate age of an air mass arriving at Mace Head. If $[\mathrm{OH}]$ is assumed to be constant (calculated from a typical average $\mathrm{OH}$ concentration measured during westerly periods of the campaign) pseudo first order kinetics can be used to give:

$\left(\frac{[\text { benzene }]}{\text { [toluene }]}\right)_{M H}=\left(\frac{[\text { benzene }]}{[\text { toluene }]}\right)_{0} \cdot \exp ^{-\left(k_{\text {benzene }}-k_{\text {toluene }}\right)[\mathrm{OH}] t}$,

where ([toluene]/[benzene] $)_{\mathrm{MH}}$ is the measured toluene:benzene ratio at Mace Head, ([toluene]/[benzene]) $)_{0}$ is the ratio at its emission source and $t$ is the time in seconds that it takes to be transported from source to the Mace Head site. Although weaknesses exist in such a technique to quantitatively determine airmass age (McKeen et al., 1996) for determining clean sector observations the $b / t$ ratio is highly sensitive to local fugitive emissions. Assuming a 4.4:1 ratio at source (London plume, summer 1988, (Penkett et al., 1993), the ratio during the more polluted periods (JD 213-217) of 1:1 corresponds to a mean age of $72 \mathrm{~h}$. In the oceanic westerly air masses at the beginning of the campaign (JD 205-209) the ratio was 1:3.7 leading to a calculated mean age of $139 \mathrm{~h}$. Using a lower starting ratio reduces this 


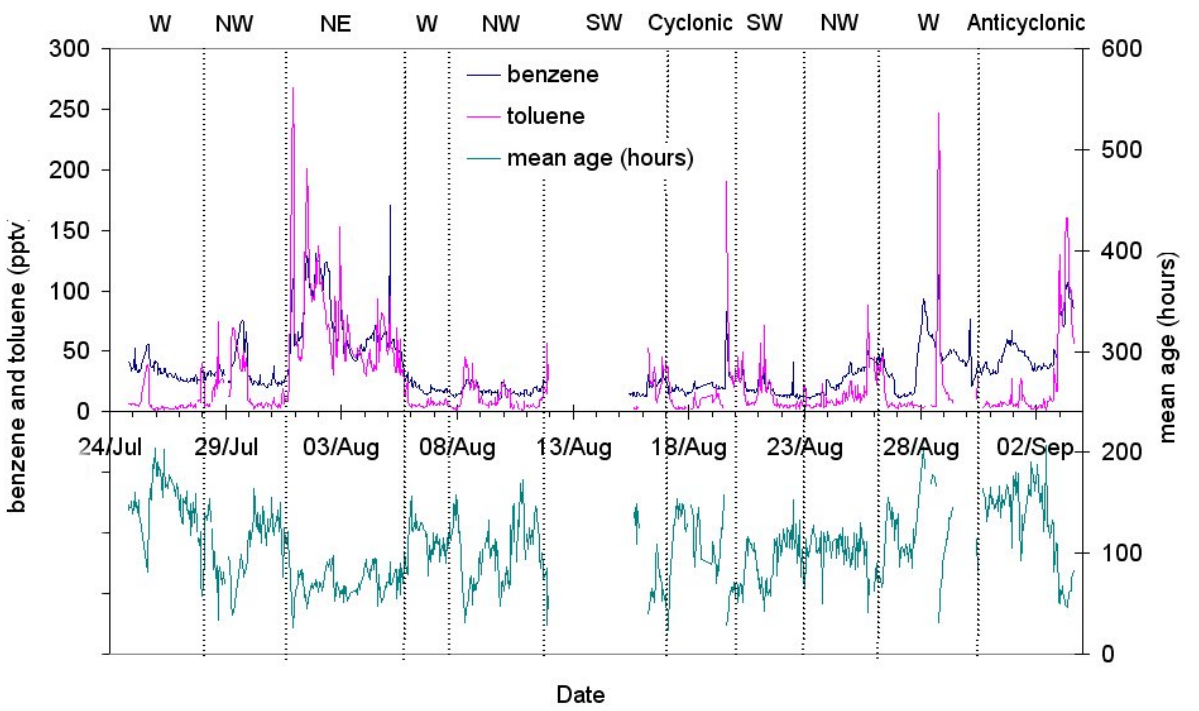

Fig. 2. Benzene and toluene observations versus day of year, used as markers for airmass pollution "age" arriving at the site. (Assumes a starting ratio of $1: 4.4$ and $[\mathrm{OH}]=1 \times 10^{6}$ molecules $\mathrm{cm}^{-3}$, rate constants from Atkinson $(1986,1989)$ Times series subdivided into periods with distinct airmass origins. Data with contradictory local wind direction / trajectory origin / chemical signatures were subsequently excluded from airmass type average calculations.

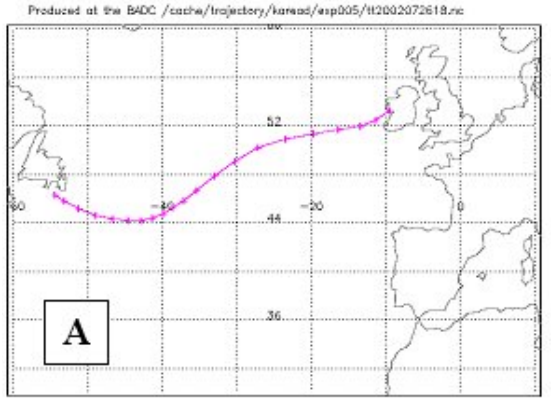

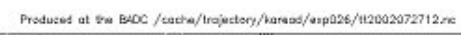

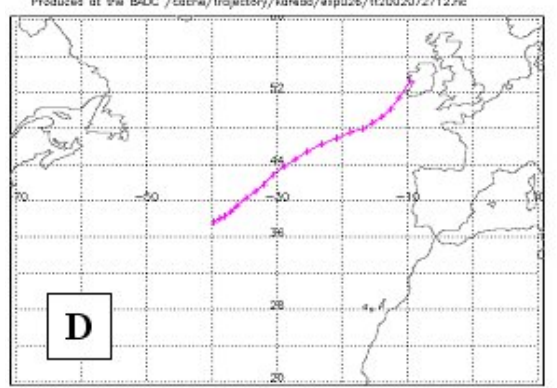

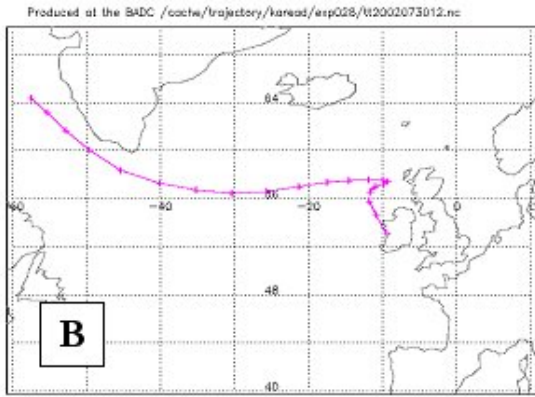

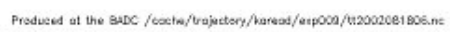

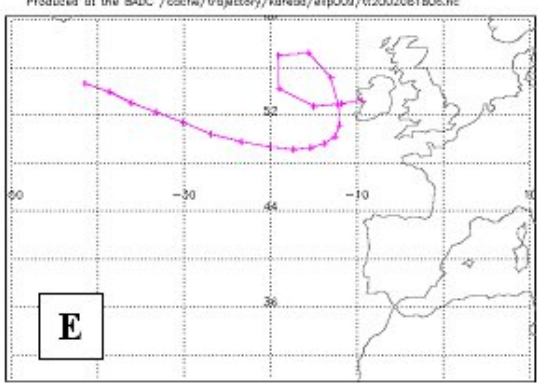

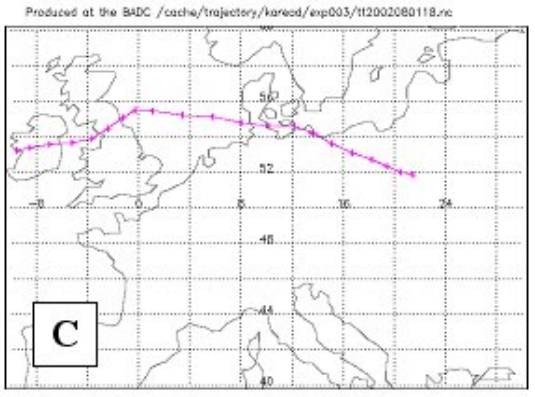

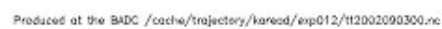

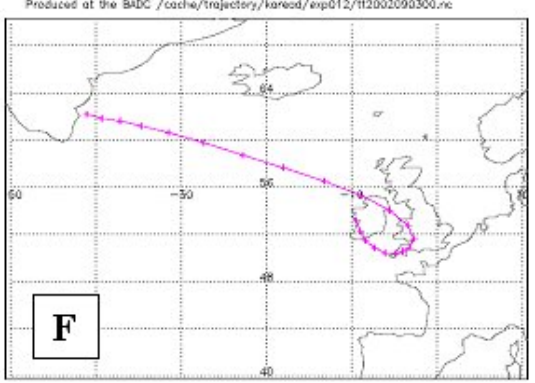

Fig. 3. Airmass trajectory classifications as used in Figs. 2 and $4, A=$ West $(W), B=$ North West (NW), C=North East (NE), D=South West (SW), E=cyclonic, and $\mathrm{F}=$ anti cyclonic

airmass age for all classifications, but for this work we are simply interested in using this changing ratio as a marker for time since the airmass received a significant input of anthropogenic organic emissions. Calculations of this kind are notably sensitive to local inputs of fresh emissions and so can act as a check for the influence of local sources. Figure 2 shows the absolute concentrations of benzene and toluene and the calculated airmass age as a function of day of year. Observations have been further classified into airmass origin using both the local meteorological data and airmass back trajectories to assign particular geographic regions from which the airmass has been transported. Figure 3 shows the classes of trajectories used. The combination of these data allows for local effects such as sea breezes to be eliminated 


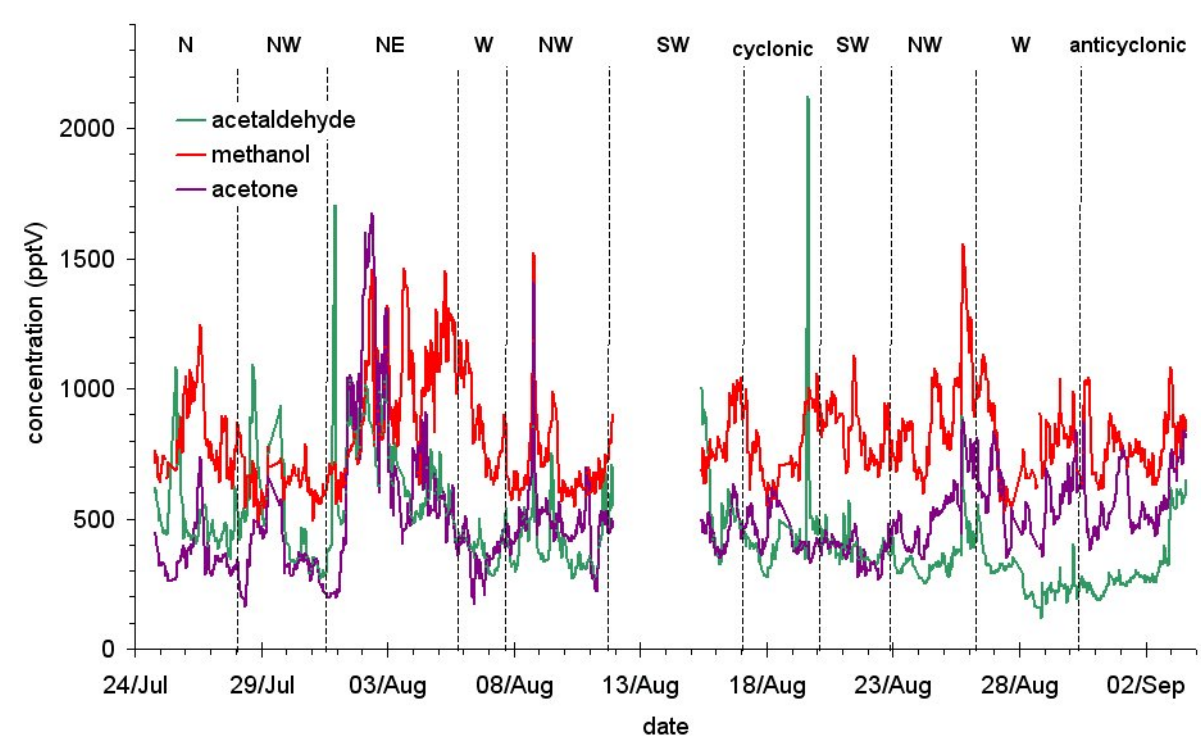

Fig. 4. Time series plot of acetaldehyde, methanol and acetone observed during the NAMBLEX campaign showing the high concentrations of these compounds under all conditions encountered.

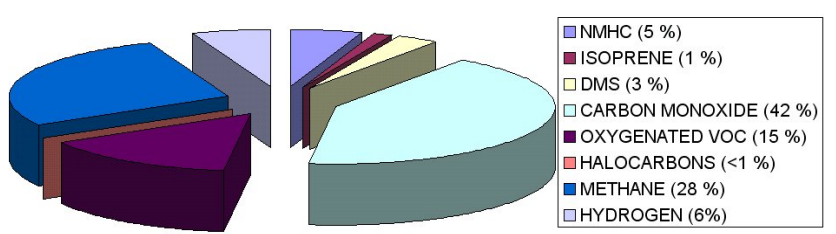

Fig. 5. Relative contribution to $\mathrm{OH}$ loss under clean southwesterly maritime conditions for NMHC, isoprene, dimethyl sulphide (DMS), carbon monoxide, oxygenated VOC (acetone+methanol+acetaldehyde), halocarbons and methane.

from grouped data classified as of clean marine origin.

\subsection{Significance of oxygenated VOC}

In air of polar, North American, and equatorial origins, acetone, methanol and acetaldehyde were found to dominate over NMHCs in terms of mass of carbon and $\mathrm{OH}$ reactivity, this observation is similar to studies such as that of Boudries et al. (2002) and Singh et al. (2001). The time series of concentrations is shown in Fig. 4, which is also annotated by airmass origin. The OVOC concentrations are similar to those previously reported in marine air and somewhat lower than observed at rural locations (summarised in Table 1). Reported mean values for acetone are significantly greater than a surface concentration of $0.3 \mathrm{ppbV}$ calculated by Singh et al. (1994) based on propane oxidation alone, implicating other precursors and sources. Large biogenic terrestrial sources have been proposed for methanol $\left(\sim 113 \mathrm{Tg}^{-1}\right)$ and acetaldehyde from pasture and plants (Kirstine et al., 1998; Galbally and Kirstine, 2002; Kesselmeier, 2001) and biomass burning sources may produce up to 10,4 and
$6 \mathrm{Tg} \mathrm{y}^{-1}$ of acetaldehyde, methanol and acetone respectively (Holzinger et al., 1999).

In marine air at Mace Head, the sum of these three compounds contributed up to $85 \%$ of the mass of measured organic carbon (excluding methane) and up to $80 \%$ of the organic hydroxyl radical sink. OH sinks used in the calculation including organic compounds, methane, hydrogen and $\mathrm{CO}$, under these conditions are shown in Fig. 5. $\left(\mathrm{NO}_{\mathrm{x}}\right.$ under maritime conditions is exceptionally low at Mace head and is not considered significant). Figure 6 shows organic primary $\mathrm{OH}$ sink percentage as a function of time, where individual compounds have been normalised to propene reactivity and grouped by compound type using;

propene-equivalent $(A)=\frac{C_{A} k_{\mathrm{OH}}(A)}{k_{\mathrm{OH}}\left(\mathrm{C}_{3} \mathrm{H}_{6}\right)}$,

where $C_{A}$ is the concentration of VOC species (in pptV), $k_{\mathrm{OH}}$ is the rate constant for the reaction between species $\mathrm{A}$ and $\mathrm{OH}$ and $k_{\mathrm{OH}}\left(\mathrm{C}_{3} \mathrm{H}_{6}\right)$ is the rate constant between propene and $\mathrm{OH}$. In reactivity terms, only during periods of significant local isoprene input does the primary hydrocarbon reactivity dominate over that of acetone, methanol and acetaldehyde, and this can be clearly seen as diurnally varying phenomena in line with expected isoprene behaviour.

\subsection{Variability-Lifetime Relationship}

Based primarily on species with longer lifetimes Junge (1974) proposed that the following inverse relationship existed between the concentration of a particular species and its variability:

$R S D_{i}=\frac{0.14}{\tau}$, 


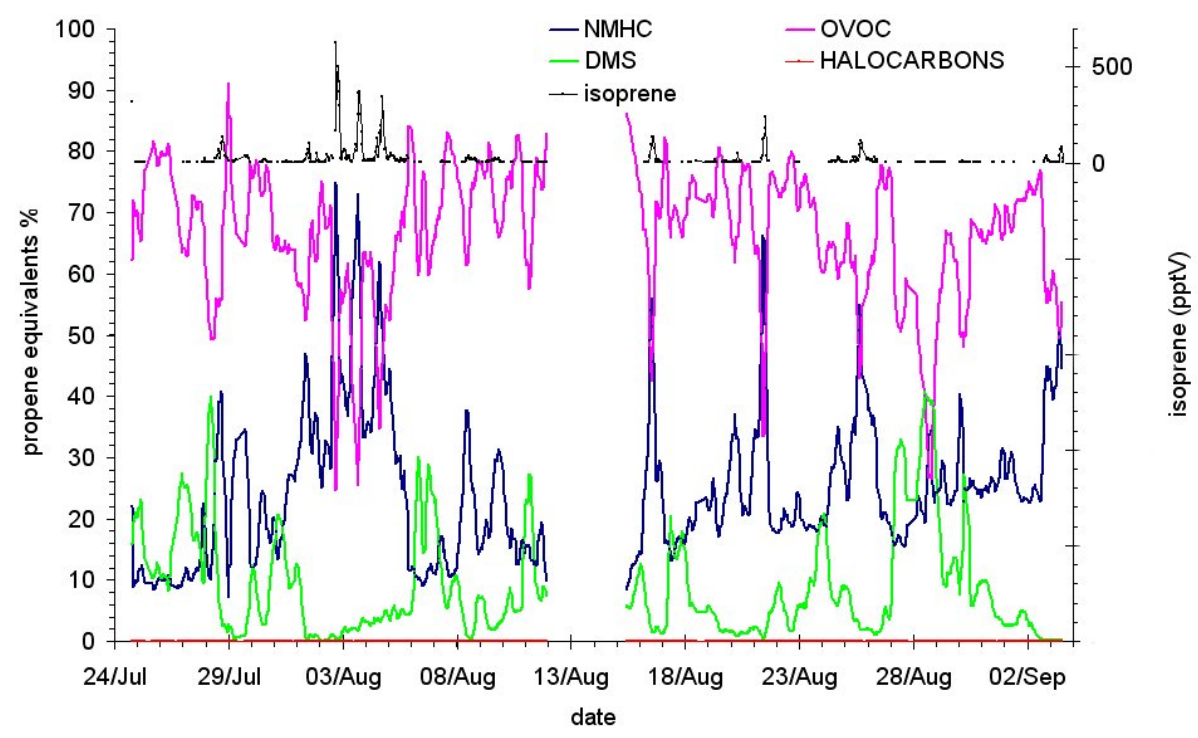

Fig. 6. Time series showing the percentage relative contribution as $\mathrm{OH}$ organic sinks for NMHC, DMS, OVOC and halocarbons $\left(\mathrm{CHCl}_{3}+\mathrm{C}_{2} \mathrm{Cl}_{4}\right)$ calculated using OH-reactivity-scaled concentrations based on propylene equivalents. Oxygenated VOCs are clearly dominant, only when isoprene levels are high does the NMHC fraction become the largest sink. The halocarbons are of minor importance to $\mathrm{OH}$ loss under these conditions.

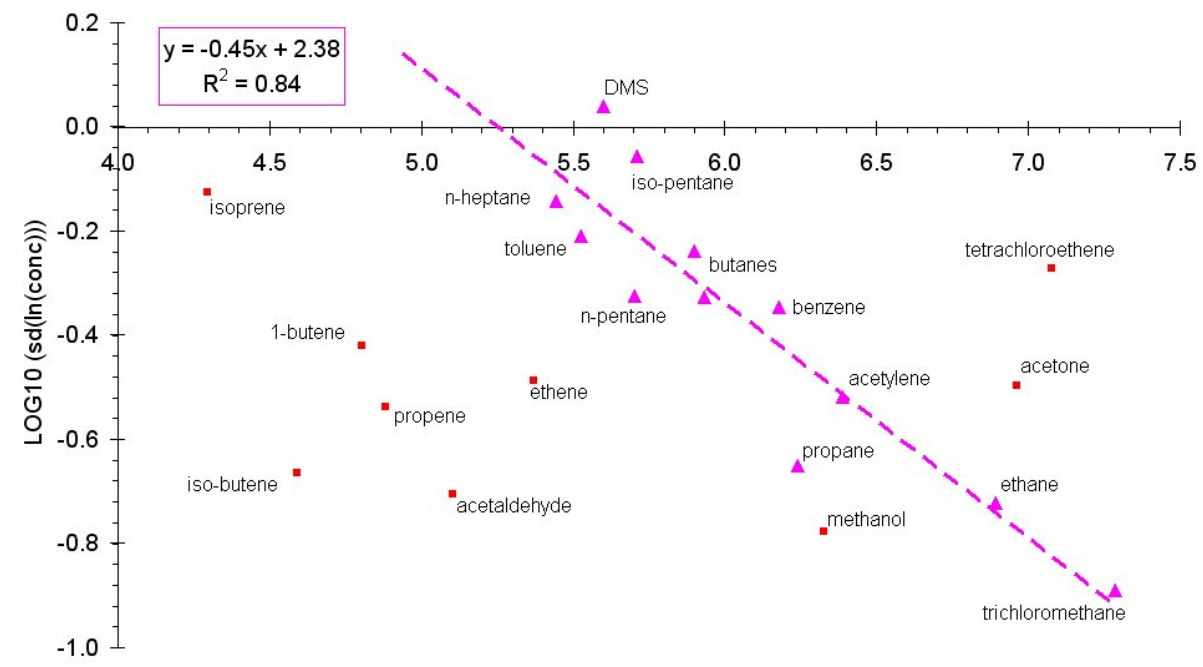

LOG10 (lifetime (s))

Fig. 7. Spatial variability-lifetime relationship for organic compounds in southwesterly air masses sampled during the NAMBLEX campaign. A linear relationship exists for some of the compounds implying common origin and major sink via reaction with $\mathrm{OH}$.

where RSD is the relative standard deviation (standard deviation divided by mean) and $\tau$ is the residence time in years using only its reaction with $\mathrm{OH}$. In later years an exponential relationship was found to be more appropriate and can be improved upon if the standard deviation of the natural $\log (\ln )$ of the concentration $S_{\ln X}$ is used instead of the relative standard deviation RSD. At long lifetimes and small variability they are roughly equivalent however $S_{\ln X}$ is more appropriate when variability is higher (Jobson et al., 1994 and Jobson et al., 1998).
$S_{\ln X i}=A \tau_{i}^{-b}$,

$\log _{10} S_{\ln X i}=\log _{10} A-b \log _{10} \tau_{i}$.

A $\log$ plot of $S_{\ln X}$ versus $t$ gives two constants A and b, which vary with source and can be used in comparisons between datasets.

A constant value of $1 \times 10^{6}$ molecules $\mathrm{cm}^{-3}$ for $\mathrm{OH}$ concentration was used as this was the average daily concentration in NAMBLEX, this leads to some uncertainty in the 
Table 1. Previous observations of acetaldehyde and acetone at selected rural sites together with this campaign.

\begin{tabular}{lccccccl}
\hline & \multicolumn{3}{c}{ acetaldehyde $(\mathrm{ppb})$} & \multicolumn{3}{c}{ acetone (ppbV) } & \multirow{2}{*}{ Reference } \\
& mean & max & min & mean & max & min & \\
\hline Rural site, Georgia, US & 0.70 & 3.80 & - & 1.80 & 6.70 & - & Lee et al. \\
Marine site, Caribbean & 0.50 & 0.94 & 0.21 & 0.40 & 0.63 & 0.18 & Zhou et al. \\
South Germany & 0.70 & 1.80 & 0.10 & 2.60 & 4.80 & 0.20 & Slemr et al. \\
Tropical Atlantic & - & - & - & 0.53 & - & - & Williams et al. \\
Mace Head & 0.44 & 2.12 & 0.12 & 0.50 & 1.67 & 0.16 & This study \\
\hline
\end{tabular}

Table 2. Initial concentrations of species used in the box model. Where: (a) corresponds to typical concentrations in the marine boundary layer and, (b) to values taken from the 3rd PORG report.

\begin{tabular}{|c|c|c|}
\hline species & concentration (pptV) & Reference \\
\hline carbon monoxide & 110000 & $\mathrm{a}$ \\
\hline nitric oxide & 220 & a \\
\hline nitrogen dioxide & 780 & $\mathrm{a}$ \\
\hline ozone & 40000 & $\mathrm{a}$ \\
\hline hydroxyl radical & 0.066 & $\mathrm{a}$ \\
\hline hydroperoxy radical & 4.94 & $\mathrm{a}$ \\
\hline methane & 1840000 & $\mathrm{~b}$ \\
\hline ethane & 2300 & $\mathrm{~b}$ \\
\hline butane & 1605 & $\mathrm{~b}$ \\
\hline acetylene & 1064 & $\mathrm{~b}$ \\
\hline ethene & 958 & $\mathrm{~b}$ \\
\hline 2-methyl butane & 947 & $\mathrm{~b}$ \\
\hline 2-methyl propane & 864 & $\mathrm{~b}$ \\
\hline propane & 824 & $\mathrm{~b}$ \\
\hline methyl benzene & 741 & $\mathrm{~b}$ \\
\hline benzene & 450 & $\mathrm{~b}$ \\
\hline hexane & 442 & $\mathrm{~b}$ \\
\hline pentane & 397 & $\mathrm{~b}$ \\
\hline 2-methyl pentane & 392 & $\mathrm{~b}$ \\
\hline 3-methyl pentane & 349 & $\mathrm{~b}$ \\
\hline butene & 269 & $\mathrm{~b}$ \\
\hline 2,2-dimethylpropane & 241 & $\mathrm{~b}$ \\
\hline 1,2-dimethyl benzene & 193 & $\mathrm{~b}$ \\
\hline ethyl benzene & 183 & $\mathrm{~b}$ \\
\hline 1,3-dimethyl benzene & 179 & $\mathrm{~b}$ \\
\hline 1,4-dimethylbenzene & 179 & $\mathrm{~b}$ \\
\hline propene & 143 & $\mathrm{~b}$ \\
\hline isoprene & 64 & $\mathrm{~b}$ \\
\hline 1-pentene & 63 & $\mathrm{~b}$ \\
\hline heptane & 42 & $\mathrm{~b}$ \\
\hline trans 2-butene & 33 & $\mathrm{~b}$ \\
\hline octane & 30 & $\mathrm{~b}$ \\
\hline cyclohexane & 28 & $\mathrm{~b}$ \\
\hline cis 2-butene & 21 & $\mathrm{~b}$ \\
\hline nonane & 13 & $\mathrm{~b}$ \\
\hline 1,3-butadiene & 12 & $\mathrm{~b}$ \\
\hline 1-hexene & 9 & $\mathrm{~b}$ \\
\hline
\end{tabular}

coefficient A, but not in the dependence of $S_{\ln X_{i}}$ on t. The use of lifetimes rather than rate constants allows easy comparison to both Junge's relationship and other reported measurements. Rate constants from Atkinson et al. $(1986,1989)$ were used to calculate the hydrocarbon lifetimes. Figure 7 shows the dependence of $S_{\ln X}$ on photochemical lifetime for data collected in southwesterly conditions. Whilst some compounds (trichloromethane, $\mathrm{C}_{2}-\mathrm{C}_{4}$ alkanes, iso-pentane, acetylene and benzene) lie on the common trend line where $\mathrm{b}=-0.45$, there are many outliers (not all shown for clarity), which do not follow this trend. For the most reactive hydrocarbon species such as ethene and propene variance is less than expected, driven by constant low background abundance, even in clean marine air, a result of slow effusion of these gases from the ocean surface to the atmosphere. Longer-lived species in general agree better with this relationship, although secondary species such as acetone, methanol and acetaldehyde are exceptions. For acetone the variance is greater than expected when compared against its lifetime with respect to $\mathrm{OH}$. This may in part be explained by other highly significant loss routes considerably reducing atmospheric lifetime from that implied by $\mathrm{OH}$ only chemistry. This would include photolysis but also potentially deposition to the sea surface. Diffuse in situ production upwind adds a further complication, producing a likely decrease in the observed variance - crudely therefore one might expect acetone to lie on the left hand rather than right hand side of the linear fit.

For acetaldehyde the variance is less than expected given its relatively short atmospheric lifetime calculated only with $\mathrm{OH}$ chemistry. Possible explanations may therefore be similar to ethene and propene in that there is a diffuse emission of this species from the sea surface in westerly conditions. The same effect may be reproduced however by atmospheric production occurring relatively close to observation location. Many studies have highlighted the possibility of reaction of ozone with artefacts deposited on the surfaces of the inlet lines leading to acetaldehyde production during sampling and hence an over estimate of the concentration of acetaldehyde in the atmosphere (Northway et al., 2004 and references therein). Williams et al. (2000) have identified such interferences as a cause for apparent low variability of acetaldehyde in the atmosphere. While instrument 
Table 3. Contribution of each parent hydrocarbon to the formation of acetone after 1, 5 and 10 days. Key intermediate species have been named where appropriate (see Appendix 1 for structures and nomenclature). Where $\mathrm{X}$ signifies the total of all other remaining sources.

\begin{tabular}{llccc}
\hline \multirow{2}{*}{ precursor } & key intermediate & \multicolumn{3}{c}{ percentage acetone formation } \\
& day 1 & day 5 & day 10 \\
\hline \multirow{2}{*}{ iso-pentane } & direct & 31.85 & 11.55 & 6.44 \\
& IPECOOH & 2.10 & 8.19 & 5.88 \\
& MIPK & 2.33 & 5.86 & 6.37 \\
& MIPK and IC3H70OH & 1.03 & 2.20 & 1.03 \\
iso-butane & direct & 25.62 & 13.83 & 11.28 \\
& TC4H9OOH & 1.36 & 8.62 & 9.19 \\
n-pentane & direct & 1.36 & 1.02 & 2.03 \\
& TC4H9OOH & 0.07 & 0.64 & 1.90 \\
propane & direct & 13.19 & 6.32 & 7.39 \\
& IC3H7OOH & 5.85 & 16.12 & 20.25 \\
2-methyl-pentane & direct & 2.79 & 0.00 & 0.00 \\
& M2PEDOOH & 0.21 & 0.00 & 0.00 \\
X & & 12.23 & 25.64 & 27.93 \\
\hline
\end{tabular}

Table 4. Contribution of each parent hydrocarbon to the formation of methanol after 1, 5 and 10 days. Key intermediate species have been named where appropriate (see Appendix 1 for structures and nomenclature). Where $\mathrm{X}$ signifies the total of all other remaining sources.

\begin{tabular}{lcccc}
\hline & & \multicolumn{3}{c}{ percentage methanol formation } \\
precursor & key intermediate & day1 & day 5 & day10 \\
\hline methane & direct & 50.00 & 64.00 & 75.00 \\
iso-butane & direct & 2.65 & 1.48 & 0.63 \\
& TC4H9OOH & 0.14 & 0.92 & 0.51 \\
iso-pentane & direct & 0.14 & 0.11 & 0.13 \\
& TC4H9OOH & 0.01 & 0.07 & 0.11 \\
acetaldehyde & direct & 14.28 & 12.50 & 6.30 \\
X & & 32.78 & 20.92 & 17.33 \\
\hline
\end{tabular}

interferences cannot be ruled out as a possible cause for this lower than expected variability, the levels of ozone recorded at the Mace Head site during the NAMBLEX campaign were relatively low compared with aircraft observations (average concentration $29 \mathrm{ppbV}$, minimum $8 \mathrm{ppbV}$ ) and so such interferences may be expected to be small for this data set. No correlation between variance and ozone concentration was observed over the range $8-50 \mathrm{ppbV}$ of ozone.

For methanol once again the variance is less than expected given its atmospheric lifetime calculated only with $\mathrm{OH}$ chemistry. Photolysis in this case is not significant, and the ocean as a source may be ruled out given those observations reported in Carpenter et al. (2004). Indeed the lifetime with respect to oceanic destruction is broadly similar to that due to atmospheric $[\mathrm{OH}]$. In this case it seems likely that the low variance may be attributed to diffuse production upwind of the measurement location.
Table 5. Contribution of each parent hydrocarbon to the formation of acetaldehyde after 1, 5 and 10 days. Key intermediate species have been named where appropriate (see Appendix 1 for structures and nomenclature). Where $\mathrm{X}$ signifies the total of all other remaining sources.

\begin{tabular}{lcccc}
\hline & & \multicolumn{3}{c}{ percentage acetalde- } \\
hyde formation & \\
precursor & key intermediate & day1 & day 5 & day10 \\
\hline n-butane & C2H5OOH & 13.41 & 18.92 & 21.08 \\
& $\begin{array}{c}\text { NC4H9OOH } \\
\text { C2H5CHO }\end{array}$ & & & \\
iso-pentane & IPECOOH & 11.29 & 11.28 & 6.23 \\
ethane & C2H5OOH & & & \\
butene & C2H5OOH & 9.49 & 17.50 & 34.51 \\
& C2H5CHO & 8.97 & 0.41 & 0.35 \\
propene & EGLYOX & & & \\
3-methyl-pentane & direct & 5.76 & 0.00 & 0.00 \\
& M3PECOOH & 5.11 & 4.62 & 1.87 \\
propane & M3PECNO3 & & & \\
pentene & C2H5OOH & & & \\
2-methyl-pentane & C2H5CHO & 3.82 & 4.44 & 6.32 \\
& C2H5CHO & 1.31 & 1.25 & 1.87 \\
X & C2H5CHO & 1.17 & 0.68 & 0.00 \\
& M2PEDOOH & & & \\
& & 39.67 & 41.48 & 27.78 \\
\hline
\end{tabular}

Clearly only qualitative conclusions may be drawn from lifetime analyses for these species, but it is helpful if only to highlight that the processing and behaviour of these species is very different to that of a primary terrestrial emission. There are clearly uncertainties relating to photolysis history of the airmass, and most importantly the effect that the ocean may have on emission or destruction of these species.

\subsection{Ocean-atmosphere exchange}

A previous paper (Carpenter et al., 2004) using this dataset has demonstrated that under certain westerly atmospheric conditions, deposition of methanol to the sea surface was occurring. A three day period of Atlantic cyclonic activity with airmasses of similar geographical origin, and where the averaged surface wind speed changed substantially as the low pressure system evolved, allowed a comparison of trace gas concentrations as a function of changing averaged surface wind speed within the boundary layer. This was highlighted by a strong anticorrelation of methanol with dimethyl sulphide, with both species showing wind speed dependence indicative of air sea exchange. Neither acetaldehyde nor acetone showed similar behaviour to methanol during this period, and a tentative conclusion may be drawn that under these particular North Atlantic conditions the ocean was not acting as a sink. DMS concentrations varied greatly during the experiment and had a strong wind speed and boundary 


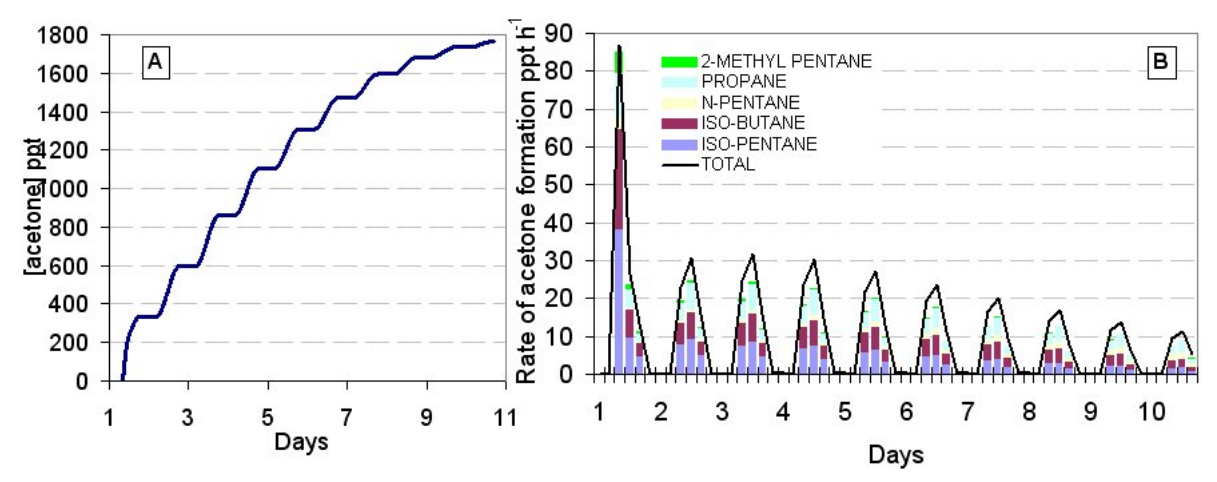

Fig. 8. (a) Box model calculation of acetone concentrations during 10 day airmass trajectory. (b) Total rate of acetone production in ppt $\mathrm{h}^{-1}$ (solid line) with individual precursor species contributions shown below as bar chart. Production exceeds destruction over the 10-day period.
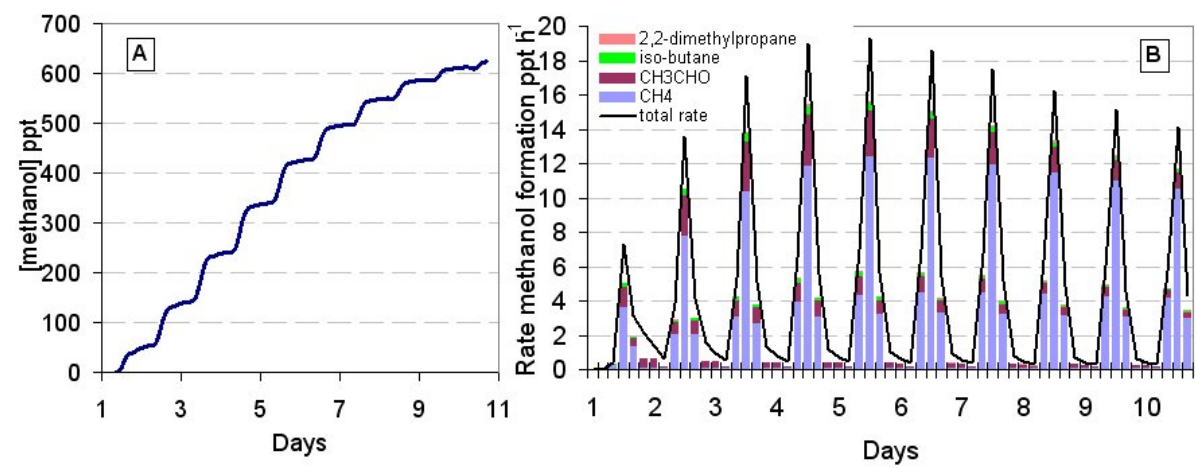

Fig. 9. (a) Box model calculation of methanol concentrations during 10 day airmass trajectory. (b) Total rate of methanol production in $\mathrm{ppt} \mathrm{h}^{-1}$ (solid line) with individual precursor species contributions shown below as bar chart. Production exceeds destruction over the 10-day period.

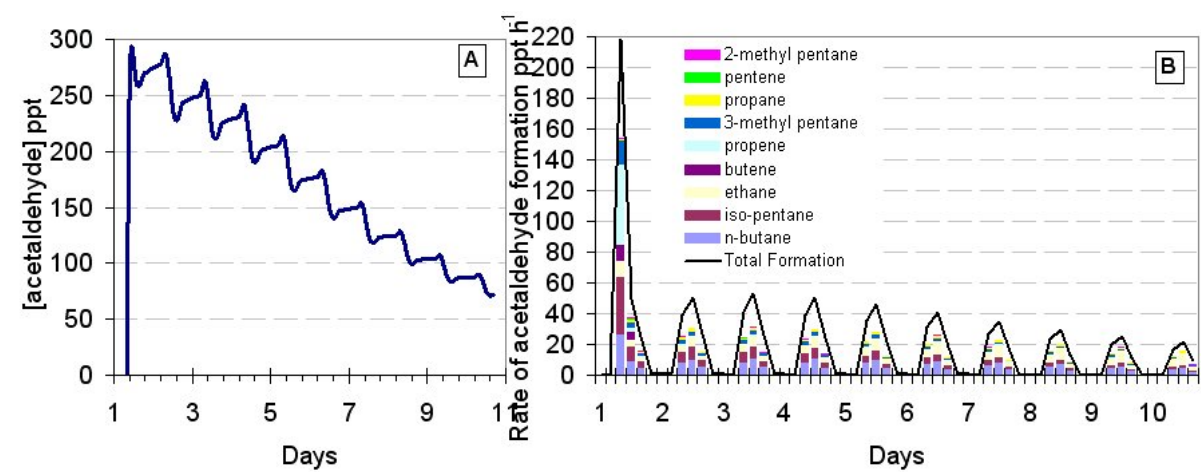

Fig. 10. (a) Box model calculation of acetaldehyde concentrations during 10 day airmass trajectory. (b) Total rate of acetaldehyde production in $\mathrm{ppt} \mathrm{h}^{-1}$ (solid line) with individual precursor species contributions shown below as bar chart. Production initially exceeds destruction, however for the majority of the 10 day period there is a general reduction in atmospheric concentrations.

layer residence time dependence, and for this experiment could be taken as an excellent proxy for active air-sea chemical exchange. From the dataset of unperturbed marine airmasses, no statistically significant relationship could be seen between ocean exchange tracers such as DMS and acetaldehyde / acetone and it would seem that the ocean (in this region and at this time) was effectively neutral in influencing atmospheric concentrations of these two OVOCs.

\subsection{Modelling study}

If direct terrestrial emission of oxygenated VOC (or rapid production following emission) were the sole source prior to long range transport, the concentrations of the most reactive oxygenated species such as acetaldehyde should be low, and with significant variance dependant on time from source to receptor. This was not recreated in our observations, and in 


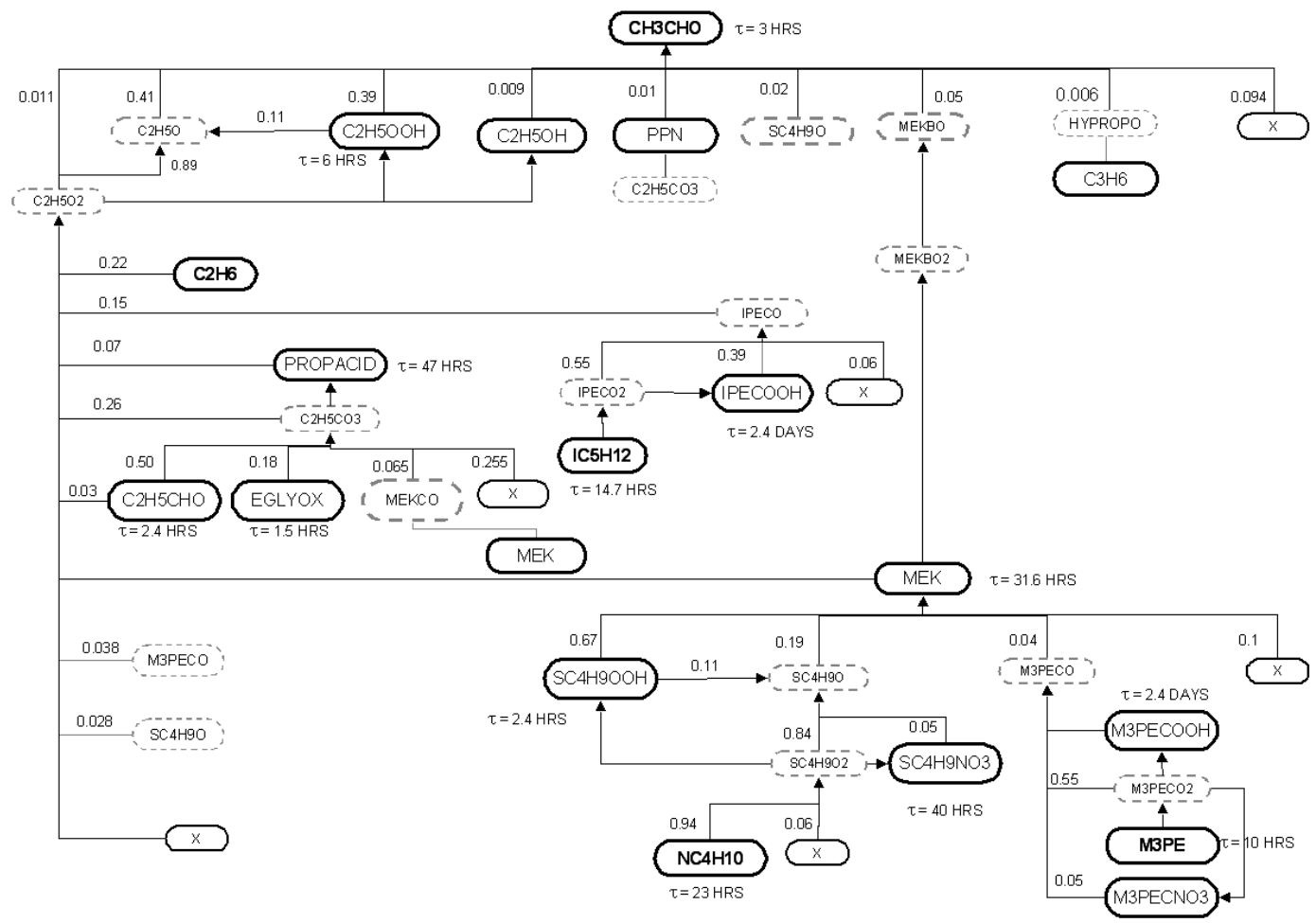

Fig. 11. Major sources of acetaldehyde on day 5. A solid border indicates stable species. The numbers on each branch signify the branching ratios for midday and the lifetimes given are also for midday. Structures and nomenclature of all species are given in Appendix 1.

the absence of an observable sea source (and with an active sink in the case of methanol), we have investigated the mechanisms for in situ atmospheric production of these species on longer timescales as an explanation for apparent persistence in the marine troposphere.

Along an air parcel trajectory the localised production rate is controlled by formation from the degradation of organic compounds, balanced by OVOC $+\mathrm{OH}$ destruction and direct photolysis. This has been studied from a chemical perspective using the Master Chemical Mechanism v3 (Saunders et al., 2003) initialised with background organic and inorganic content representative of fresh emissions leaving a continental landmass (Table 2). This zero dimensional box is allowed to chemically evolve over a period of 10 days, typical of very long-range intercontinental zonal transport, and the results can be seen in Figs. 8a, 9a and 10a for acetone, methanol and acetaldehyde respectively. Acetone concentrations (Figs. 8a and b) were predicted to increase during the day and remain constant at night, where overall net increases in atmospheric concentration were still occurring at the end of the 10-day period. The rate of production had slowed markedly by the 10th day with the rate of formation approaching the rate of atmospheric removal by $\mathrm{OH}$ and photolysis. Methanol (Figs. 9a and $b$ ) behaved in a similar manner to acetone, with a steady build-up in concentration over time, but with net production occurring after 10 days. The sustained production of methanol is clearly due to its dominant precursor, methane, which is both long lived and globally distributed, but it is worth noting that the non-methane organic contribution to methanol production is still significant several days downwind. The increase in production rate of methanol to its maximum at around day 5 is driven primarily by increases in calculated $[\mathrm{OH}]$.

One of the major uncertainties in the model predictions for methanol production is the rate of the $\mathrm{CH}_{3} \mathrm{O}_{2}+\mathrm{RO}_{2}$ reaction since relatively few kinetic data are available. The reaction rate used in the model is $7.6 \times 10^{-13} \mathrm{~cm}^{3} \mathrm{~mol}^{-1} \mathrm{~s}^{-1}$ provided by the MCM protocol (Jenkin et al., 1997). The $\mathrm{CH}_{3} \mathrm{O}_{2}+\mathrm{RO}_{2}$ reaction rates were changed within the model to investigate their effect on methanol production. Decreasing and increasing this rate of reaction by $50 \%$ had a substantial effect on the methanol concentration producing a 42 $\%$ decrease and a $33 \%$ increase in methanol concentrations respectively over a ten day period.

The profile for acetaldehyde (Figs. 10a and b) is significantly different to both methanol and acetone with an initial rapid increase in concentration and then net destruction over days $2-10$. The key difference for acetaldehyde is its shorter atmospheric lifetime, where removal rate exceeds production with the exception of around midday. Although the calculated concentrations of acetaldehyde decrease downwind, the daytime production from intermediates helps mitigate some of these losses, extending the influence of this species for many days longer than would otherwise be the case. 
Air masses arriving at the site will have been subject to a variety of meteorological conditions, however the model runs were performed at constant temperature $(290 \mathrm{~K})$ and pressure (760 mbar). The pressure, temperature and water vapour concentration dependence of OVOC levels predicted by the model has been investigated; it was found that varying the pressure and water vapour concentration has little effect (for example a $5 \%$ decrease in relative humidity and pressure results in a maximum change of 3 and $7 \%$ respectively in OVOC concentrations), but variations in temperature can yield dramatic changes in predicted concentrations, for example a $5 \%$ decrease in temperature produces a $47 \%$ increase in acetaldehyde over a ten day period.

Whilst not providing a rigorous estimation of absolute concentrations at any point in time, since dilution and mixing are ignored (particularly important to methanol and acetone which almost certainly have non-zero background concentrations), this model allows for the important precursor species in the production process, the rate determining steps, and reservoirs of stable intermediates to be identified. It also provides a guide to the timescales of secondary oxygenate production relative to destruction.

Using detail from the MCM, calculations indicate that surprisingly small subsets of hydrocarbon precursors are responsible for much of the in situ production of all three oxygenated species. Tables 3, 4 and 5 show the major precursor compounds for the in situ generation of acetone, methanol and acetaldehyde respectively. Figures $8 \mathrm{~b}, 9 \mathrm{~b}$ and $10 \mathrm{~b}$ show the speciated chemical formation rate of acetone, methanol and acetaldehyde respectively from point of emission day 1 to day 10 including some detail of the diurnal profile in the production rate of these compounds.

The individual reactions in the production process have been tracked using the MCM and Fig. 11 illustrates a typical flow chart showing acetaldehyde production routes 5 days after emission. All species show most rapid generation within the first 6-12 $\mathrm{h}$ following emission, however OVOC production rate as a function of time since emission does not follow the first order decay in precursor hydrocarbon concentration. Significant formation rates are maintained throughout the simulated 10-day chemical evolution sustained by the relatively long atmospheric lifetimes of some intermediate compounds formed in the degradation process. The formation of reservoir species such as organic peroxides and long chain alcohols coupled with the slow feed-through of higher molecular weight oxidation products, themselves generated from larger hydrocarbons extends the timescale for production very significantly beyond the lifetime of the original hydrocarbon precursor. It is significant that many of the longer lifetime intermediates such as organic peroxides and large alcohols are not currently measured, and their observations would be very beneficial in trying to determine the full extent of possible in situ production.

\section{Conclusions}

Observations of acetone, methanol, acetaldehyde and a range of non-methane hydrocarbons have been made in North Atlantic marine air at the Mace Head observatory. Acetone, methanol and acetaldehyde were found to be highly significant in terms of total mass of organics and their contribution to $\mathrm{OH}$ radical loss when compared with all other reactive organic compounds measured at this location. Deposition of methanol to the sea surface was suggested during a period of continued cyclonic activity (Carpenter et al., 2004), but there was no evidence within this dataset to suggest similar behaviour for acetone and acetaldehyde. Longer time series measurements would help to determine this conclusively. Chemical production routes for methanol, acetone and acetaldehyde were investigated and the key precursor species identified as a relatively small subset of non-methane hydrocarbons, in addition to other OVOCs. The large number of steps and the existence of stable oxidative intermediates in the in situ generation of OVOCs may explain both our observations and others, which have shown substantial concentrations of high reactivity OVOCs in airmasses that have been unperturbed for many days. A lack of observational techniques for these species is clearly a major gap in verifying such conclusions. The mechanisms for oxygenate production demonstrates that secondary chemistry must be explicitly considered when attempting to calculate the abundance of such species in the background atmosphere, and that the full accounting of high molecular weight species may well be essential if the feed-through of carbon to smaller forms such as these is to be correctly modelled. 
Appendix A: Chemical structures and nomenclature

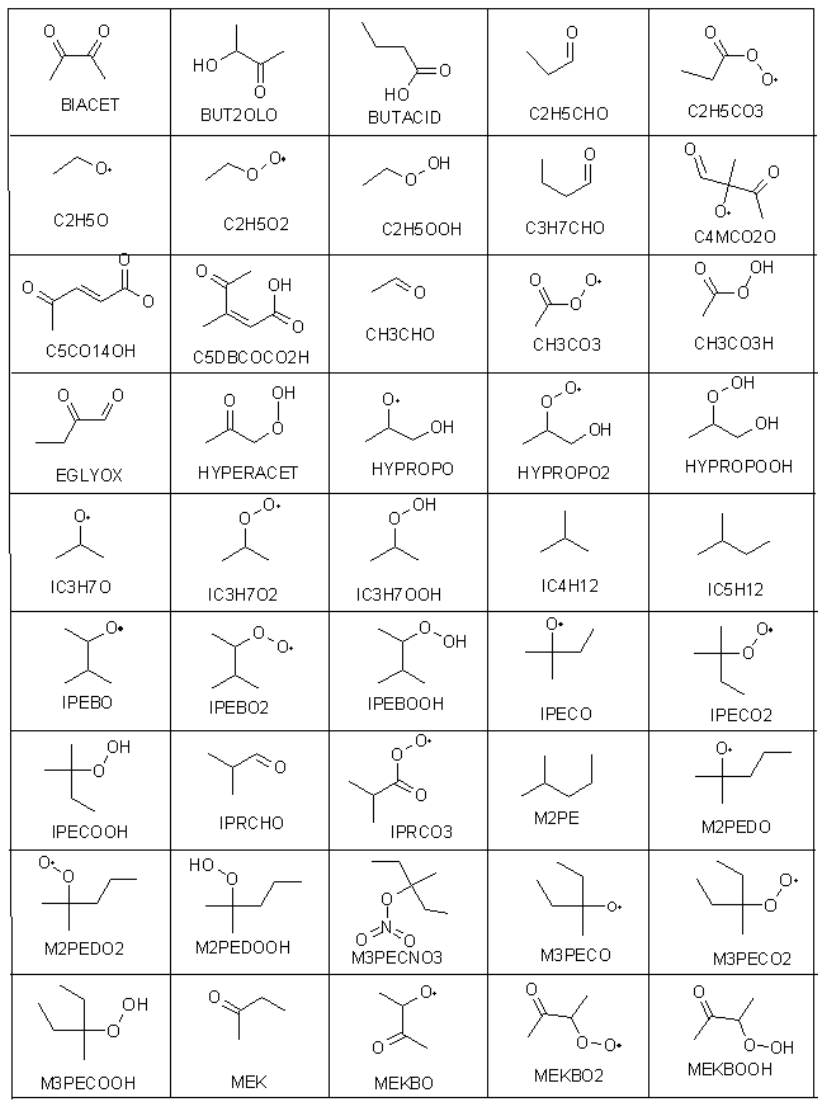

Fig. A1.

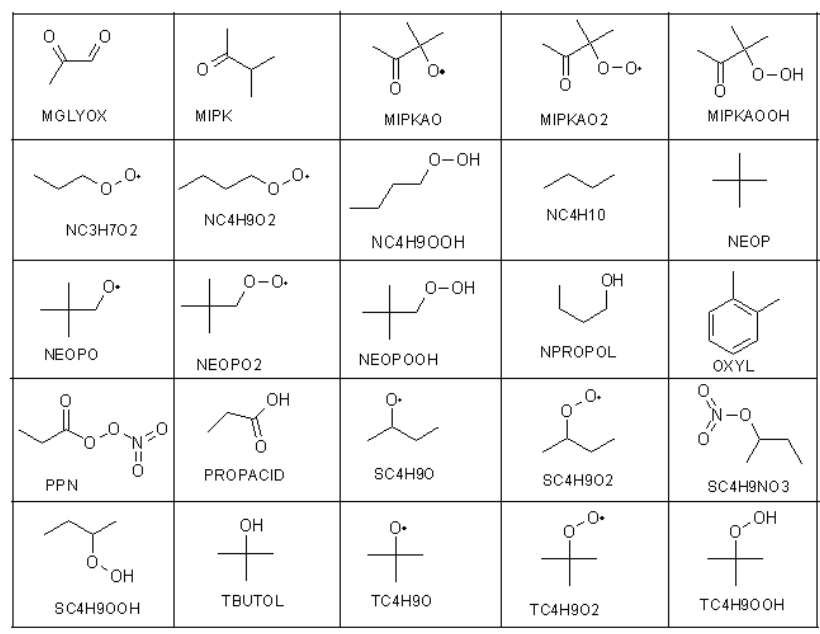

Fig. A2.
Acknowledgements. The authors would like to thank G. Spain (University of Galway), site manager of Mace Head atmospheric observatory, and D. Heard (University of Leeds), NAMBLEX principal investigator, for their support throughout the field study. NERC provided funding for the project and the British Atmospheric Data Centre for providing data management.

Edited by: D. Heard

\section{References}

Atkinson, R.: Kinetics and mechanisms of the gas phase reactions of the hydroxyl radical with organic compounds under atmospheric conditions, Chem. Rev., 86, 69-201, 1986.

Atkinson, R., Baulch, C. L., Cox, R. A., Hampson, R. F., Kerr, J. A., and Troe, J.: Evaluated kinetic data for atmospheric chemistry 3. IUPAC subcommittee on gas kinetic data evaluation for atmospheric chemistry, J. Phys. Ch. R., 18, 881-1097, 1989.

Boudries, H., Bottenheim, J. W., Guimbaud, C, Grannas, A. M, Shepson, P. B., Houdier, S., Perrier, S., and Domine, F.: Distribution and trends of oxygenated hydrocarbons in the high Arctic derived from measurements in the atmospheric boundary layer and interstitial snow air during the ALERT2000 field campaign, Atmos. Envir., 36, 2573-2583, 2002.

Carpenter, L. J., Lewis, A. C., Hopkins, J. R., Read, K. A., Gallagher, M., and Longley, I.: Uptake of methanol to the North Atlantic ocean surface, Global Biog., 18, 2004.

Carslaw, N., Bell, N., Lewis, A. C., McQuaid, J. B., and Pilling, M. J.: A detailed case study of isoprene chemistry during the EASE96 Mace Head campaign, Atmos. Envir., 34, 2827-2836, 2000.

Department of the Environment Transport and the Regions: Ozone in the United Kingdom, fourth report of the Photochemical Oxidants Review Group, 1997.

Galbally, I. E. and Kirstine, W.: The production of methanol by flowering plants and the global cycle of methanol, J. Atmos. Chem., 43, 195-229, 2002.

Hamilton, J. F. and Lewis, A. C.: Monoaromatic complexity in gasoline and urban air using GCxGC and GC-TOF-MS, Atmos. Envir., 37, 589-602, 2003.

Heard, D. E.: The North Atlantic Marine Boundary Layer Experiment (NAMBLEX), Mace Head, summer 2002, Campaign overview, same issue, 2005.

Holzinger, R., Warneke, C., Hansel A., Jordan, A., Lindinger, W., Scharffe, D. H., Schade, G., and Crutzen, P. J.: Biomass burning as a source of formaldehyde, acetaldehyde, methanol, acetone, acetonitrile, and hydrogen cyanide, Geophys. Res. Lett., 26, 1161-1164, 1999.

Hopkins, J. R., Read, K. A., and Lewis, A. C.: A two column method for long-term monitoring of non-methane hydrocarbons (NMHCs) and oxygenated volatile organic compounds, J. Envir. Mon., 5, 8-13, 2003.

Jacob, D. J., Field, B. D., Jin, E. M., Bey, I., Li, Q. B., Logan, J. A., Yantosca, R. M., and Singh, H. B.: Atmospheric budget of acetone, J. Geophys. Res.-A., 107, 2002.

Jenkin, M. E., Saunders, S. M., Derwent, R. G., Pilling, M. J.: Construction and application of a master chemical mechanism (MCM) for modelling tropospheric chemistry. Atmos. Env., 31, 81-104, 1997 
Jennings, S. G., Spain, T. G., Doddridge, B. G., Maring, H., Kelly, B. P., and Hansen, A. D. A.: Concurrent measurements of black carbon aerosol and carbon monoxide at Mace Head, J. Geophys. Res.-A., 101, 19447-19454, 1996.

Jobson, B. T., Niki, H., Yokouchi, Y., Bottenheim, J., Hopper, F., and Leaitch, R.: Measurements of C2-C6 hydrocarbons during the polar sunrise 1992 experiment: evidence for $\mathrm{Cl}$ atom and $\mathrm{Br}$ atom chemistry, J. Geophys. Res.-A., 99, 25 355-25 368, 1994.

Jobson, B. T., Parrish, D. D., Goldan, P., Kuster, W., Fehsenfeld, F. C., Blake, D. R., Blake, N. J., and Niki, H.: Spatial and temporal variability of non-methane hydrocarbon mixing ratios and their relation to photochemical lifetime, J. Geophys. Res.A., 103, $13557-13567,1998$.

Junge, C. E.: Residence time and variability of tropospheric trace gases, Tellus, 26, 477-488, 1974.

Kesselmeier, J.: Exchange of short-chain oxygenated volatile organic compounds (VOCs) between plants and the atmosphere: A compilation of field and laboratory studies, J. Atmos. Chem., 39, 219-233, 2001.

Kirstine, W., Galbally, I., Ye, Y. R., and Hooper, M.: Emissions of volatile organic compounds (primarily oxygenated species) from pasture, J. Geophys. Res.-A., 103, 10 605-10 619, 1998.

Lee, Y. N., Zhou, X., and Hallock, K.: Atmospheric carbonyl compounds at a rural southeastern United States site, J. Geophys. Res.-A, 100, 25 933-25 944, 1995.

Lewis, A. C., Bartle, K. D., Heard, D. E., McQuaid, J. B., Pilling, M. J., and Seakins, P. W.: In situ, gas chromatographic measurements of non-methane hydrocarbons and dimethyl sulfide at a remote coastal location (Mace Head, Eire) July-August 1996, J. Chem. Soc., Faraday T., 93, 2921-2927, 1997.

Mckeen, S. A., Liu, S. C., Hsie, E. Y., Lin, X., Bradshaw, J. D., Smyth, S., Gregory, G. L., and Blake, D. R.: Hydrocarbon ratios during PEM-WEST A: A model perspective, J. Geophys. Res.A., 101, 2087-2109, 1996.

Northway, M. J., de Gouw, J. A., Fahey, D. W., Gao, R. S., Warneke, C., Roberts, J. M., and Flocke, F.: Evaluation of the role of heterogeneous oxidation of alkenes in the detection of atmospheric acetaldehyde, Atmos. Envir., 38, 6017-6028, 2004.

Penkett, S. A., Blake, N. J., Lightman, P., Marsh, A. R. W., and Anwyl, P.: The seasonal variation of non-methane hydrocarbons in the free troposphere over the north Atlantic ocean: Possible evidence for extensive reaction of hydrocarbons with the nitrate radical, J. Geophys. Res.-A., 98, 2865-2885, 1993.
Salisbury, G., Williams, J., Holzinger, R., Gros, V., Mihalopoulos, N., Vrekoussis, M., Sarda-Esteve, R., Berresheim, H., von Kuhlmann, R., Lawrence, M., and Lelieveld, J.: Ground-based PTR-MS measurements of reactive organic compounds during the MINOS campaign in Crete, July-August 2001, Atmos. Chem. Phys., 3, 925-940, 2003,

SRef-ID: 1680-7324/acp/2003-3-925.

Saunders, S. M., Jenkin, M. E., Derwent, R. G., and Pilling, M. J.: Protocol for the development of the Master Chemical Mechanism, MCM v3 (Part A): tropospheric degradation of nonaromatic volatile organic compounds, Atmos. Chem. Phys., 3, 161-180, 2003,

SRef-ID: 1680-7324/acp/2003-3-161.

Singh, H. B., Ohara, D., Herlth, D., Sachse, W., Blake, D. R., Bradshaw, J. D., Kankidou, M., and Crutzen, P. J.: Acetone in the atmosphere - Distribution, sources and sinks, J. Geophys. Res.A., 99, 1805-1819, 1994.

Singh, H. B., Chen, Y., Staudt, A., Jacob, D., Blake, D. R., Heikes, B., and Snow, J.: Evidence from the Pacific troposphere for large global sources of oxygenated organic compounds, Nature, 410, 1078-1081, 2001.

Singh, H. B., Tabazadeh, A., Evans, M. J., Field, B. D., Jacob, D. J., Sachse, G., Crawford, J. H., Shetter, R., and Brune, W. H.: Oxygenated volatile organic chemicals in the oceans: Inferences and implications based on atmospheric observations and air-sea exchange models, Geophys. Res. Lett., 30, 2003.

Slemr, J., Junkermann, W., and Volz-Thomas, A.: Temporal variations in formaldehyde, acetaldehyde and acetone and budget of formaldehyde at a rural site in southern Germany, Atmos. Envir., 30, 3667-3676, 1996.

Wevill, D. J. and Carpenter, L. J.: Automated measurement and calibration of reactive volatile halogenated organic compounds in the atmosphere, Analyst, 129, 634-638, 2004.

Williams, J., Fischer, H., Harris, G. W., Crutzen, P. J., Hoor, P., Hansel, A., Holzinger, R., Warneke, C., Lindinger, W., Scheeren, B., and Lelieveld, J.: Variability-lifetime relationship for organic trace gases: A novel aid to compound identification and estimation of HO concentrations, J. Geophys. Res.-A., 105, $20473-$ $20486,2000$.

Williams, J., Holzinger, R., Gros, V., Xu, X., Atlas, E., and Wallace, D. W. R.: Measurements of organic species in air and sea water from the tropical Atlantic, Geophys. Res. Lett., 31, 2004.

Zhou, X. and Mopper, K.: Carbonyl compounds in the lower marine troposphere over the Caribbean Sea and Bahamas, J. Geophys. Res.-A., 98, 2385-2392, 1993. 